\title{
OPTICAL AND RELATED PROPERTIES OF SEMICONDUCTORS: BULK AND SMALL PARTICLES
}

\author{
G.C. PAPAVASSILIOU \\ Theoretical and Physical Chemistry Institute, \\ National Hellenic Research Foundation, \\ 48, Vassileos Constantinou Ave., Athens 116/35, Greece
}

\begin{abstract}
A 3STRACT. The similarities and dissimilarities in the optical and related properties of conventional (e.g. CdS) and unconventional (i.e. metal-halide chain complexes, organic ion radical salts, polymers etc) semiconductors (bulk and small particles) are reviewed and some recent results are briefly reported. The blue shift of the excitonic or charge transfer bands, by decreasing the size of the particles, is a common feature in the spectra of this kind of materials.
\end{abstract}

\section{Introduction}

The spectra of semiconductors have more than one peak caused by several different mechanisms such as phonons (lattice vibrations) and excitons (bound electron-hole pairs).In the ultraviolet-visible-nearinfrared spectral region, the more interesting peaks are those arising from excitonic and other states inside the gap as well as from exciton-phonon interactions[1]. The optical absorption (OA) spectra of semiconductor particles show particle-size effects. Such effects, arising from the size quantization of excitonic states, have been observed for the first time by Berry [2] and then by the author [3] and Ekimov et al [4], independently. The author confirmed Berry's results by parallel observations of OA spectra, photoluminescence (PL) spectra and resonance Raman excitation (RRE) profiles of CdS particles [3]. The first theoretical descriptions (of quantum confinement of semiconductor excitons in all spatial dimensions) were given by Efros and Efros [5] as well as by Brus et al [6]. Since then, several research groups have studied linear and nonlinear optical properties of a number of three-dimensional (3-D) semiconductors finely dispersed in liquids glasses, polymers etc (see [7-13] and refs therein). Also, properties of quasi-two-dimensional (q-2-D) or two-dimentional (2-D) semiconductors, such as $\mathrm{PbI}_{2}, \mathrm{PbI}_{4}{ }^{2-}$, have been reported $[14,15]$. In the mid years, similar effects in the spectra of one-dimensional (1-D) semiconductors (i.e. metal-halid chain complexes, organic ion radical salts, etc) have been observed [16-26]. In this paper, the similarities and dissimilarities in the optical and related properties (OA,PL, resonance Raman (RR)spectra and RRE profiles) of several compound semiconductors (bulk and small particles) are reviewed and some recent results are briefly reported. Observations at room temperature are mainly discussed.

\section{Cadmium Sulfide (CdS) and Similar Compounds}

It is well known that CdS is crystallized in the hexagonal or cubic system, but there

G. C. Hadjipanayis and R. W. Siegel (eds.), Nanophase Materials, 493-502.

1994 Kluwer Academic Publishers. Printed in the Netherlands. 
are no significant differences in the optical properties of these two phases in the optical range close to the gap energy, $\mathrm{E}_{\mathrm{g}}(=2.55 \mathrm{eV}, 486 \mathrm{~nm})$. The compound is a 3-D semiconductor with a weak anisotropy. It is a direct-gap semiconductor. Fig. 1a shows the OA spectra of a thick single-crystal specimen of (hexagonal) CdS with thickness of $0.89 \mu \mathrm{m}$. They were observed with light polarized parallel (II) and perpendicular $(\perp)$ to the c-axis (see [2] and refs therein). The slight hump or shoulder at ca $2.52 \mathrm{eV}$ is due to (Wannier) free-excitons. It becomes sharper and is shifted to higher energies at low temperatures. The value of excitonic energy $\left(E_{e x}\right)$, corresponding to the lowest level, is given by the following equations (see [1])

$$
E_{c x}=E_{g}-E_{b} ; E_{b}=e^{2} / 2 \varepsilon r ; r=\varepsilon h^{2} / \mu e^{2}
$$

where $E_{b}$ is the binding energy of exciton, $e$ is the electron charge, $\varepsilon$ is the dielectric constant of material (e.g. CdS), $\mathrm{r}$ is the (effective) Bohr exciton radius and $\mu$ is the reduced mass given by $1 / \mu=1 / \mathrm{m}_{\mathrm{e}}+1 / \mathrm{m}_{\mathrm{e}}\left(\mathrm{m}_{\mathrm{e}_{\mathrm{e}}}\right.$ is the electron mass and $\mathrm{m}_{\mathrm{h}}$ is the hole mass). For $\mathrm{CdS}, \mathrm{E}_{\mathrm{b}}=30 \mathrm{meV}$ and $2 \mathrm{r}=60 \AA$. The excitonic structure is more pronounced in the PL spectra and RRE profiles of CdS. PL spectra give also information on some other states inside the gap. Fig.1b shows the PL spectra of a single crystal of $\mathrm{CdS}$ for parallel and perpendicular polarizations. The bands at ca. $505 \mathrm{~nm}$ (band-edge emission) are due to free-excitons, the weak bands at ca $555 \mathrm{~nm}$ (shallowtrap emission) may be due to polaron- or impurity-states [3], and the bands (at ca $705 \mathrm{~nm}[3,8]$ )(deep-trap emission) are due to self-trapped excitons associated with the lattice imperfections (only the high energy tails are shown in Fig.1).The longituclinal optical (LO)-phonon modes in the RR spectra of CdS occur at ca $305 \mathrm{~cm}^{-1}$ (see below, Fig. 2).Fig. Ic shows the RRE profiles (i.e. the variations of intensity of LOphonon modes with the energy of the exciting light) of CdS for both polarizations.Because of the strong exciton-phonon interactions, the RRE profiles show maxima near the excitonic absorption band [1]. When the crystal thickness is of the order of the Bohr exciton diameter, the excitonic shoulders or bands are strongly shifted to higher energies with simultaneous broadening of the gap (see [1] refs cited in[3] herein). Similar shifts have been observed in the spectra of small particles of $\mathrm{CdS}$ and similar compounds [2-13,26]. Samples of small particles of CdS have been mainly prepared by reaction of $\mathrm{Cd}^{2+}$ with $\mathrm{H}_{2} \mathrm{~S}$ in liquids, polymers etc. Thin deposits of $\mathrm{CdS}$ particles on quartz or $\mathrm{CaF}_{2}$ plates have been prepared by similar methods [3]. In most cases, the samples consist of spherical particles with a wide size distribution. Fig. 1a' and Fig. 1a' 'show the OA spectra of CdS deposits, consisting of small particles of ca $100 \AA$ [3] and ca $70 \AA$ [26] diameter, respectively . One can see that the excitonic shoulder is shifted to higher energies as the particlesize decreases. The effects are more pronounced in the PL spectra as well as in RRE profiles of 1LO-phonon mode [3], as it is shown in Figs. 1b', $1 b^{\prime}$ ' and $1 c^{\prime}, 1 c^{\prime}$, respectively. The excitonic bands occur at $468 \mathrm{~nm}$ and $460 \mathrm{~nm}$ in the PL spectra of small particles of ca $100 \AA$ and ca $70 \AA$, respectively. The PL bands of particles with size of $40,200,1000$ and $1500 \AA$ occur at $450,480,496$ and $500 \mathrm{~nm}$, respectively [26] (see also [6,8]). Similar results were obtained from the RRE profiles (Figs. $\left.1 c^{\prime}, 1 c^{\prime} '[3,26]\right)$. The broadening of the bands in the spectra of small particles is mainly due to the wide particle-size distribution (see [12]). The PL shoulder at ca 550 $\mathrm{nm}$ (shallow-trap emission) becomes more pronounced and the intensity of excitonic peak decreases after heat treatment. This is due to the increase of $\mathrm{Cd}$ concentration $[3,8]$. In some samples of CdS and other semiconductors, the excitonic PL band is very weak. It has been shown that the poor excitonic luminescence of small parti- 

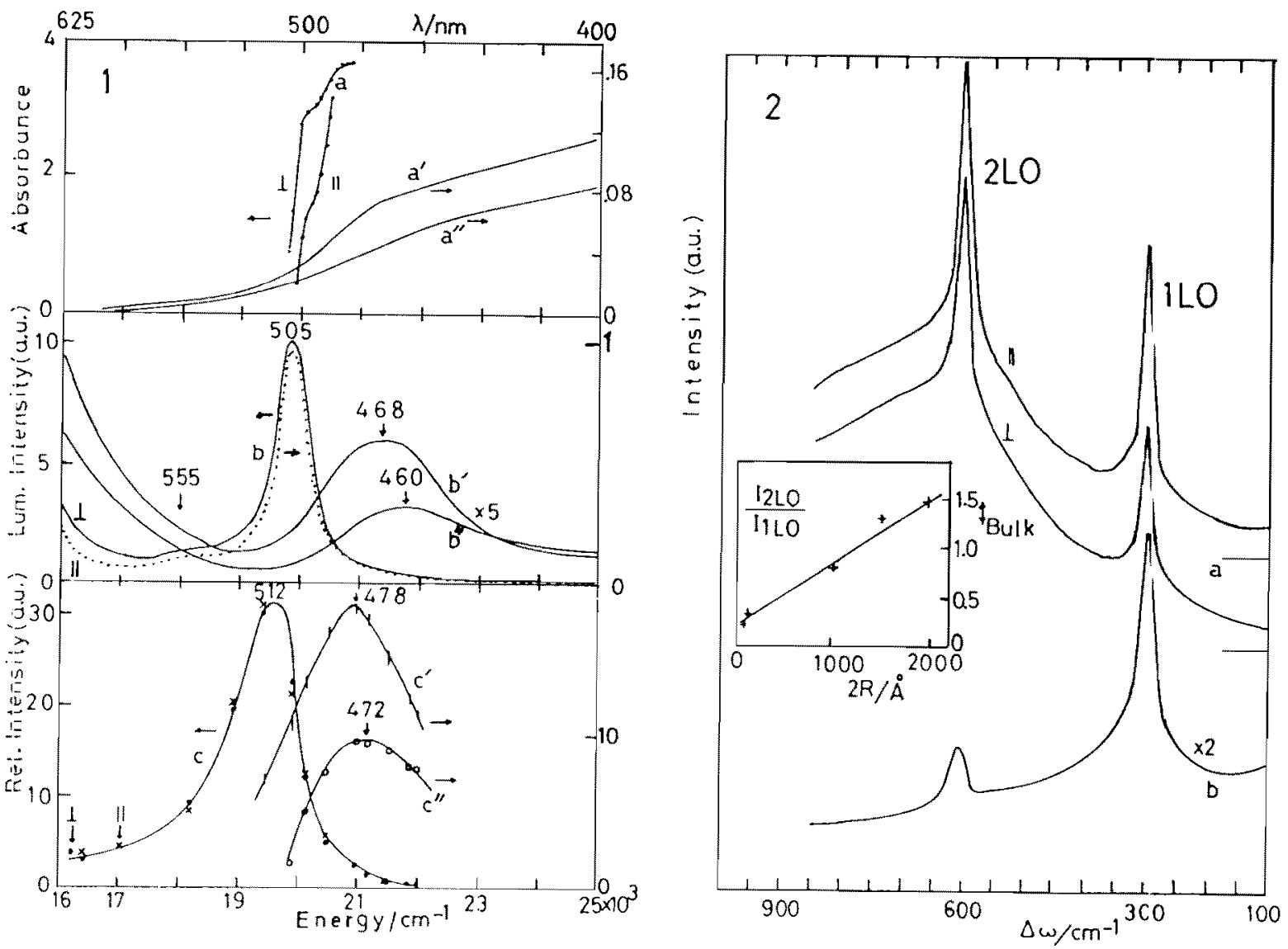

Fig. 1.OA (a, $\left.a^{\prime}, a^{\prime \prime}\right), P L$ ( $\left.b, b^{\prime}, b^{\prime \prime}\right)$ spectra and RRE profiles(c, $\left.c^{\prime}, c^{\prime \prime}\right)$ of a single-crystal specimen $(0.89 \mu \mathrm{m})$ of $C d S$ (a) (see [2]), of a (thicker) single-crystal of CdS $(b, c)[26]$, of a thin deposit of CdS particles (ca 100 $\AA$ ) on quartz plate $\left(a^{\prime \prime}, b^{\prime}, c^{\prime}\right)[3]$ and of a thin deposit of $C d S$ particles (ca $70 \AA)$ on $C a F_{2}$ plate $\left(a^{\prime \prime}, b^{\prime \prime}, c^{\prime \prime}\right)$ [26].

Fig. 2. $R R$ spectra of a single crystal of CdS(a) [26] and of a deposit of small CdS particles (ca $100 \AA$ ) (excitation line $488 \mathrm{~nm}$ ) [3]. The particle-size dependence of $I_{2 I} \mathcal{O}^{\prime} I_{1 L O}$ is shown in the insert $[3,24,26]$.

cles is due to intrinsic or extrinsic effects [8] or to the increased nonradiative decay in excitons at surfaces $[8,9]$. The nature of the surrounding medium plays an important role in the intensity of PL bands. Quantum-size effects have been mainly studied by OA and PL spectroscopy $[1-8,10]$. When there are exciton-phonon interactions (as in CdS), RR spectroscopy is extremely effective for the study of quantum size effects. Fig. 2 shows the particle size effects in the intensities of RR spectra and details in PL spectra near the excitation line $(488 \mathrm{~nm})$. One can see that, in single crystal, the intensity (I) of 2LO-phonon mode is higher than that of the 1LO-phonon mode for both polarizations, while, in the case of small particles of CdS (ca $100 \AA$ ), the result is opposite. When the particle size is (close to and) larger than the Bohr exciton-diameter, a linear relationship of the ratio $A=I_{21 . O} / I_{1 L}$ versus particle size has been obtained (see insert in Fig. 2) $[24,26]$, namely, A decreases as particle-size decreases. Because of the exciton-phonon interactions, the following equation was found for the excitonic energy $\left(\mathrm{E}_{\mathrm{cx}}\right)$ (see [9] and refs cited therein):

$$
E_{c x}=E_{i}-2 E_{1 . O}+B(1 / A)^{1 / 2}
$$


(where $E_{\mathrm{i}}$ is the energy of excitation-line and $\mathrm{B}$ is a constant). From this equation and the experimental data of Fig. 2 (insert), one can find that $E_{\text {ex }}$ increases as the particle-size decreases. The $E_{\text {ex }}$ values are plotted versus $2 R$ in Fig. 3 together with those obtained from PL spectra. The $\mathrm{E}_{\text {ex }}$ values are compared to those obtained from quantum mechanical calculations. For spheres with diameter (2R) much larger than the Bohr exciton diameter (:weak confinement or exciton confinement), the following equation has been found $[5,13]$ :

$$
E_{c x}=E_{g}-E_{b}+h^{2} \pi^{2} / 2\left(m_{e}+m_{h}\right) R^{2}
$$

For spheres with diameter much smaller than the Bohr diameter (:strong confinement or confinement of individual particles) the following equation has been found $[6,13]$ :

$$
E_{e x}=E_{g}-0.248 E_{b}+h^{2} \pi^{2} / 2 \mu R^{2}-1.786 e^{2} / \varepsilon R
$$

More complicated formulas, which cover a wide range of $R$, are given in the literature. For a spherical-dielectric continuum model (SDCM), for example, see [13]. The results of calculation are plotted in Fig.3, for comparison with experimental points obtained from the RR intensities and PL band positions. One can see that for
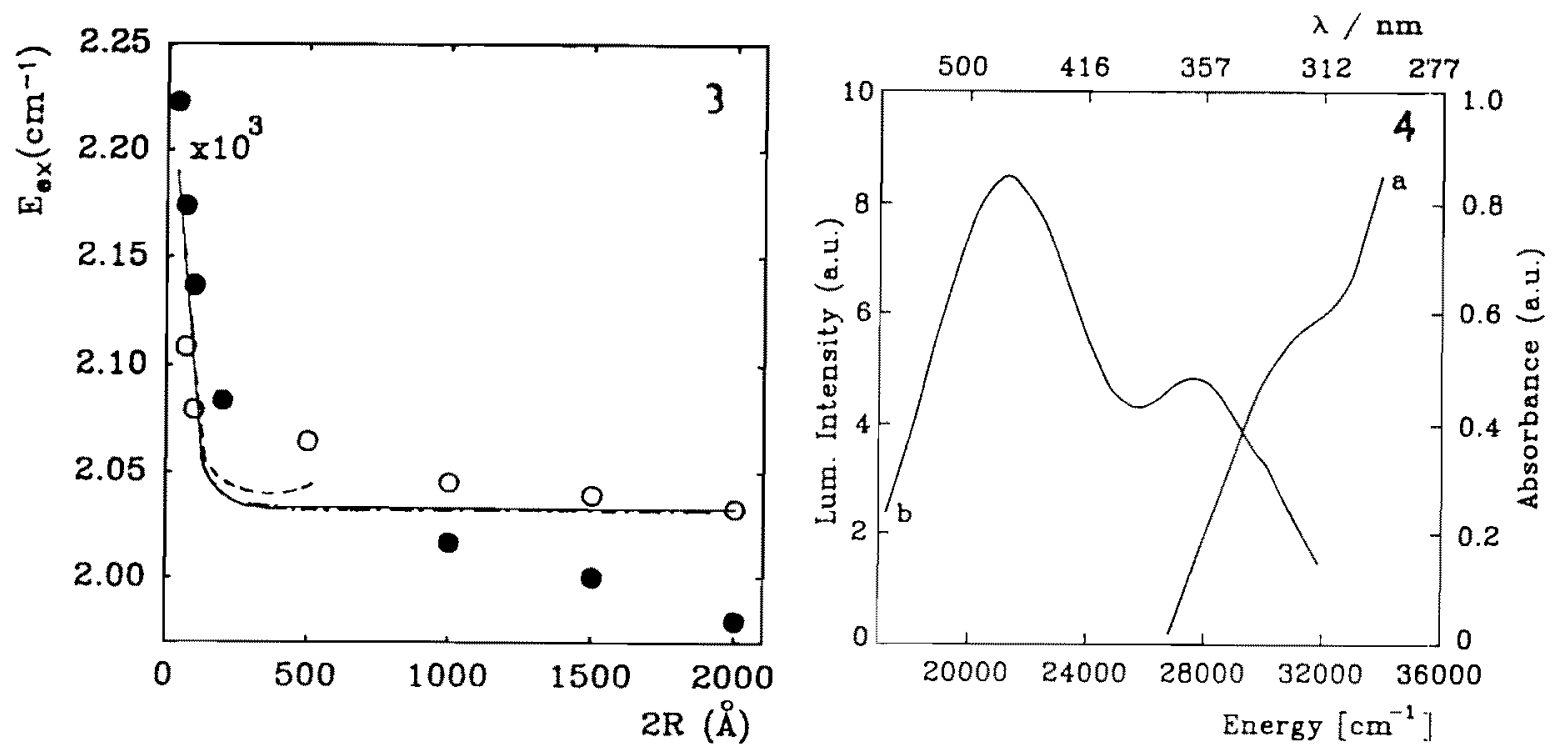

Fig.3. Particle-size dependence of the excitonic energy $\left(E_{c x}\right)$ of CdS particles, obtained from experimental data of Fig.2 (insert) and eqn (2) (open circles) as well as that obtained from PL spectra (closed circles). Solid line presents the calculated values using SDCM, dashed line presents the calculated from eqn (3) and dashed-dotted from eqn (4).

Fig. 4. OA (a) and PL (b) spectra of $C d_{X} S_{y}(S P h)_{z}$ clusters (7Å<2R<10Ä) in tetrahydrofurane (:clusters obtained by electrolytic method) [26].

particles with $40 \AA<2 R<1000 \AA$ the results from both $R R$ and PL spectra obey the quantum mechanical theories. Consequently, RR spectroscopy could be suggested as a method for investigation of guantum size effects, especially in the cases for which PL spectra are weak and OA spectra are difficult to be observed. Recently, quantum size effects, in particles with size much smaller than the Bohr-exciton diameter, have been reported (see [10-13]). Also recently, semiconductor clusters of the formula $\mathrm{Cd}_{\mathrm{x}} \mathrm{A}_{\mathrm{y}}(\mathrm{SPh})_{\%},(\mathrm{~A}=\mathrm{S}, \mathrm{Se})$ have been prepared and their properties studied (see 
$[11,12,26])$. They were prepared from $\left[\mathrm{Cd}_{10} \mathrm{~A}_{4}(\mathrm{SPh})_{16}\right]^{4-}[11]$ by heating at ca $250^{\circ}$ $C[12,26]$, by electrolysis in acetonitrile [26] and by treatment with $\mathrm{Na}_{2} S$ [12]. The OA spectrum of $\mathrm{Cd}_{\mathrm{x}} \mathrm{S}_{\mathrm{y}}(\mathrm{SPh})_{\mathrm{z}}$, obtained by the first method, with a core $\left(\mathrm{Cd}_{\mathrm{x}} \mathrm{S}_{\mathrm{y}}\right)$ smaller than $10 \AA$, shows an excitonic peak at $346 \mathrm{~nm}$ [12], while the corresponding PL spectrum shows only a broad band at ca $480 \mathrm{~nm}$ (shallow-trap emission), as in the case of heated samples of $\mathrm{CdS}$ particles. The blue shift may be due to size quantization of the shallow-trapped states [8]. However, the OA spectrum of similar clusters, abtained by the electrolytic method [26], shows an excitonic band (at $320 \mathrm{~nm}$ ), while the corresponding PL spectrum shows both the excitonic band (at $360 \mathrm{~nm}$ ) and the shallow-trap emission band (at $470 \mathrm{~nm}$ ). The corresponding spectra are shown in Fig.4. The OA spectra of monodisperse clusters (prepared by treatment with $\mathrm{Na}_{2} \mathrm{~S}$ ) show sharp excitonic bands, as they are needed for technological applications [12].

\section{3. $\left(\mathrm{CH}_{3} \mathrm{NH}_{3}\right) \mathrm{SnBr}_{3}$ and similar compounds}

$\left(\mathrm{CH}_{3} \mathrm{NH}_{3}\right) \mathrm{SnBr}_{3}$ has a cubic perovskite structure. It is a (synthetic) 3-D semiconductor. A weak particle size effect has been observed in the spectra of $\left(\mathrm{CH}_{3} \mathrm{NH}_{3}\right) \mathrm{SnBr}_{3}$ and similar materials (with I, instead of $\mathrm{Br}$, and /or $\mathrm{Pb}$, instead of $\mathrm{Sn}$ ) [15].The OA spectrum of a thin film of this compound shows an excitonic shoulder at $560 \mathrm{~nm}$ and the PL spectrum shows a band at $579 \mathrm{~nm}$ (film)or $590 \mathrm{~nm}$ (single: crystal).

\section{Lead Iodide $\left(\mathrm{PbI}_{2}\right),\left(\mathrm{C}_{n} \mathrm{H}_{2 \mathrm{n}+1} \mathrm{NH}_{3}\right)_{2} \mathrm{PbI}_{4}$ and similar compounds}

$\mathrm{FbI}_{2}, \mathrm{HgI}_{2}$, and $\mathrm{BiI}_{3}$ are layered $\mathrm{q}-2-\mathrm{D}$ semiconductors. Quantum size effects in the $\mathrm{OA}$ and PL spectra have been reported in refs [14]. Also, $\left(\mathrm{C}_{\mathrm{n}} \mathrm{H}_{2 \mathrm{n}+1} \mathrm{NH}_{3}\right)_{2} \mathrm{PbI}_{4}$ (and similar compounds with $\mathrm{Cl}$ and $\mathrm{Br}$ instead of $\mathrm{I}$ and/or $\mathrm{Sn}$ instead of $\mathrm{Pb}$ ) are (synthetic) 2-D semiconductors (natural quantum wells) with interesting linear and nonlinear optical properties (see [15] and refs cited therein). In these compounds, the perovskite-like 2-D networks of $\mathrm{PbI}_{4}$ correspond to quantum wells, while the alkylammonium chains play the role of barriers and sandwich the wells. In the limit of strong confinement, the binding energy of 2-D systems is four times larger than that cif 3-D systems [27]. In the present case, the binding energy is $240-360 \mathrm{meV}$ and the corresponding Bohr-exciton radius is $18-12 \AA$. The OA and PL spectra of small particles or thin films showed excitonic bands at higher energies and sharper than those of the single crystals. The bands show sharp absorption feature [15] as in the monodisperse CdS clusters [12]. However, it is not clear yet if the shifts in the bands are due to the size quantization of excitonic levels. The reason is the smaller Bohr-exciton radius, which means that one needs samples with very small particles in order to observe strong particle-size effects in the OA and PL spectra. The corresponding 2D artificial systems based on GaAs/ AlGaAs show quantum size effects after etching the wells to form quantum wires and quantum dots, because the excitonic diameter (2r) of wells is large (ca $200 \AA$ ) [27]. In the present case, perhaps because of the weak exciton-phonon interactions, RR spectra are not observed at room temperature, but only the shallow-trap emission can be observed in the PL spectra of doped samples $[14,15,26]$.

\section{Pt(en $)_{2} \mathrm{Pt}(\mathrm{en})_{2} \mathrm{Cl}_{2}\left(\mathrm{ClO}_{4}\right)_{4}$ and similar compounds}

$\mathrm{Pt}(\mathrm{en})_{2} \mathrm{Pt}(\mathrm{en})_{2} \mathrm{Cl}_{2}\left(\mathrm{ClO}_{4}\right)_{4}$ (where en=ethylenediamine), referred to hereafter as $\mathrm{PtCl}$, 
is crystallized as red or greenish needle-like plates, in which the b-axis is the needleaxis. The crystals consist of $\mathrm{Pt}{ }^{\mathrm{II}}(\mathrm{en})_{2}$ and $\mathrm{Pt}^{\mathrm{IV}}(\mathrm{en})_{2}$ units, which are stacked alternatively along the $\mathrm{b}$-axis, constructing a linear chain of $\mathrm{Cl}-\mathrm{Pt} \mathrm{II}_{-}-\mathrm{Cl}-\mathrm{Pt}^{\mathrm{IV}}-$ segments (see for example[28]). It behaves as an 1-D semiconductor (: natural quantum wires system). It is a Peierls distorted system with strong electron-phonon (e-p) interactions. Some NiBr-analogs do not show Peierls distortion and are characterized as Hubbard insulators, in which the 1-D instability due to e-p is suppressed by the on-site e-e Coulomb repulsion energy $(U)$ on Ni site. Since the observation of 1$\mathrm{D}$ semiconductor character of $\mathrm{PtCl}$ and the particle size effects in the optical properties of $\mathrm{PtCl}$ and similar compounds [19], several research groups have studied linear and nonlinear optical properties of these materials, in single crystal form or in powdered form (see [20-22, 24-36] and refs therein). Fig.5a ${ }_{1}$ shows the OA spectrum of a greenish single crystal of $\mathrm{PtCl}$ with polarization parallel to the chain axis, obtained by Kramers-Krönig transformation of the corresponding reflectance spectrum [20].The strong band at $454 \mathrm{~nm}$ is a charge transfer band (CTB) with a CTB-edge, $E_{\mathrm{o}}^{\prime}=2.5 \mathrm{eV}$ $(495 \mathrm{~nm})$. Some weak bands or shoulders at lower energies were initially attributed to (Wannier) excitons [20,22], but subsequent experiments and theoretical calculations showed that the lowest energy bands are due to polarons, bipolarons, solitons etc (see [23-29]).Also, electroabsorption and other experiments as well as theoretical calculaticns have showed that there exist one odd-parity (optically allowed)excitonic peak at ca $480 \mathrm{~nm}$ and one even-parity (forbidden) excitonic peak at higher energy close to $\mathrm{E}_{\mathrm{g}}$ [29-31]. In the 1-D systems, because of the infinite value of excitonic binding energy, the excitonic peaks should occur far from $\mathrm{E}_{\mathrm{g}}[27,32]$ but, in the case of $\mathrm{PtCl}$, some broadening mechanism (such as e-p interactions) amalgamates the excitonic peaks into a single broad band (CTB) [31]. Perhaps, the broadening of CTB is also due to the wide distribution of the segment-length, in accordance with the results obtained from a variety of single crystals $[20,24]$. The OA spectrum of another crystal of $\mathrm{PtCl}$, which is red in colour, with $\mathrm{E}_{\mathrm{g}}^{\prime}=2.72 \mathrm{eV}(456 \mathrm{~nm})$, shows a maximum at 423 $\mathrm{nm}$ (Fig.5a $\mathrm{a}_{2}$ ). The OA spectrum of small PtCl-particles (ca $80 \AA$, suspensions in $\mathrm{CCl}_{4}$ or deposits on quartz plates) $[19,20]$, shows a maximum at $410 \mathrm{~nm}$ (Fig.5a'). The PL spectrum shows a strong band at ca $1000 \mathrm{~nm}[20,33]$ (only the high energy tail is shown in Fig.5), which is due to self-trapped excitons. It does not exhibit particle size effects, perhaps because of small Bohr radius. The weak shoulders $(690-770 \mathrm{~nm})$ correspond to the polaronic absorption peaks. The stronger shoulder at $540 \mathrm{~nm}$, which is shifted to longer wavelengths $(512 \mathrm{~nm})$ in the spectrum of small particles, may be due to free-excitons ( $\mathrm{Fig} .5 \mathrm{~b}_{1}, \mathrm{~b}_{2}, \mathrm{~b}^{\prime}$ ). The observed poor luminescence is due to intrinsic or extrinsic effects as in the case of $\mathrm{CdS}$ [8].A shift in the corresponding RRE profiles of $\mathrm{PtCl}\left(\mathrm{Fig}_{5} 5 \mathrm{c}_{1}, \mathrm{c}_{2}, \mathrm{c}^{\prime}\right.$ see also $[19,33]$ ) as in the case of $\mathrm{CdS}$, can be considered as a consequence of the exciton-1LO-phonon interactions, because their positions occur close to the odd-parity excitonic peak. Both, PL spectrum and RRE profiles are shifted to higher energies as the particle size of $\mathrm{PlCl}$ decreases, as in the case of CdS. The PL spectra of PtCl (single crystals and small particles) doped with $\mathrm{PdCl}$ show a band at ca $720 \mathrm{~nm}$ (shallow-trap emission) [26] similar to that observed in the dcped CdS samples. RRS of a single crystal and small particles as well as the particle-size dependence of $\mathrm{I}_{2 \mathrm{~L} . \mathrm{O}} \mathrm{I}_{11 . \mathrm{O}}$ in $\mathrm{PtCl}$ are shown in Fig.6. The particle size dependence of the excitonic energy $\left(\mathrm{E}_{\mathrm{ex}}\right)$ of $\mathrm{PtCl}$ particles is shown in Fig.7. The results are similar to those of CdS (Figs.3,4). However, in contrast to the spectra of $\mathrm{CdS}$, the first overtone (2LO) in RR spectra of $\mathrm{PtCl}$ was never observed higher than the fundamental (ILO) [24], perhaps because of the short-segments structure of $\mathrm{PtCl}$ 

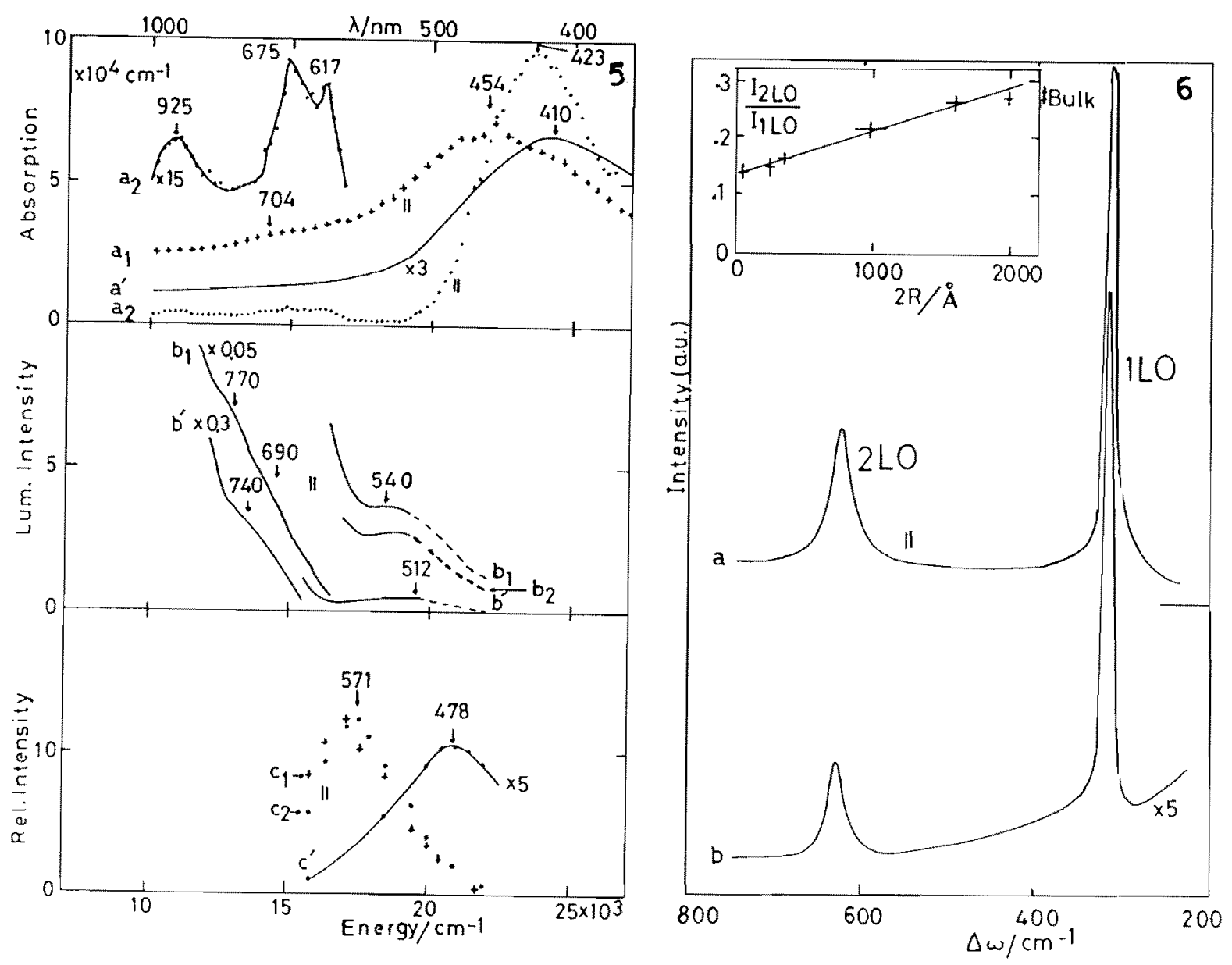

Fig.5. OA ( $\left.a_{1}, a_{2}, a^{\prime}\right), P L\left(b_{1}, b_{2}, b^{\prime}\right)$ spectra (the Raman lines have been eliminated) and $R R E$ profiles $\left(c_{1}, c_{2}, c^{\prime}\right)$, of a greenish single crystal $\left(a_{1}, b_{1}, c_{1}\right)$ of a red single crystal $\left(a_{2}, b_{2}, c_{2}\right)$, and of small particles $\left(a^{\prime}, b^{\prime}, c^{\prime}\right)$ of Pt Cl (from $[19,20,24,26]$ ).

Fig.6.Same as in Fig.2, but for PtCl and excitation 454.5nm (from $[19,20,24,261$ ).

sirgle crystals. There is also a small shift of the Raman lines (LO, 2LO etc) of PtCl and a larger one in PtBr-analogs to higher (Raman) frequencies as the particle size decreases ([19-22], see also [34,35]). A broadening of the excitonic bands is a consequence of the wide particle (segment) size distribution. Each segment has a specific LO-mode, the corresponding OA spectrum and RRE profile. In other words, several segments with different lengths show different resonance Raman lines; each one of these lines comes into the resonance at different excitation energies. But, because of the e-p broadening mechanism and/or the wide particle-size distribution in the samples, a broad RRE profile was obtained. Similar results were obtained from other $\mathrm{MX}$ (metal-halide chain)-systems ( $\mathrm{M}=\mathrm{Ni}, \mathrm{Pd}, \mathrm{Pt} ; \mathrm{X}=\mathrm{I}, \mathrm{Br}, \mathrm{Cl})$ as well as from mixedhalide, mixed-ligand and mixed-metal analogs [19-26]. Crystals of $\operatorname{PtBr}\left(\mathrm{E}_{\mathrm{g}}^{\prime}=1.5 \mathrm{eV}\right)$ are green in colour and become violet after grinding,with OA maxima at 690 and 530 $\mathrm{nm}$, respectively. Crystals of $\mathrm{PtI}\left(\mathrm{E}_{\mathrm{g}}^{\prime}=1.2 \mathrm{eV}\right)$ are golden and become blue after grinding,with OA maxima at 1100 and $750 \mathrm{~nm}$, respectively. Because of the large differences in $E_{g}$, MX compounds have been used for preparation of 1-D superlattices. Superlattices of single crystals of mixed-halide $\mathrm{MX}_{\mathrm{x}} \mathrm{X}_{1-\mathrm{X}}$ materials are repor-ted in $[1,34-36]$. They consist of segments of pure $M X$ and $\mathrm{MX}^{\prime}$ producing junctions between the distinct halide segments. The optical and related properties depend on the 
nature of $\mathrm{M}, \mathrm{X}, \mathrm{X}^{\prime}$ as well as the concentration, namely the segment length. The following systems have been extensively studied: $\mathrm{PtCl}_{x} \mathrm{Br}_{1-x}, \mathrm{PtCl}_{x} \mathrm{I}_{1-x}$ and $\mathrm{PtBr}_{x} \mathrm{I}_{1-\mathrm{x}}$, for a variety of concentrations $(\mathrm{x})$. It was found that $\mathrm{Pt} \mathrm{X}_{\mathrm{x}} \mathrm{I}_{1-\mathrm{x}}$ chain materials are 1-D analogs of p-n junctions [34,36]. Calculated OA spectra of single crystals and small particles can be obtained using extended Peierls-Hubbard model [18,26, 28, 29] with the appropriate values of $U$ and/or other parameters.

\section{KTCNQ and similar compounds}

$\mathrm{KTCNQ}$ (where TCNQ=tetracyanoquinodimethane) is crystallized as needle-like plates with a copper-Justre. The crystals are composed of 1-D columns of TCNQ molecules, which stand face to face along the a-axis. Complete charge transfer takes place between the TCNQ molecules and $\mathrm{K}$; the electrons are nearly localized on TCNQ molecules due to large on-site Coulomb energy $(\mathrm{U} \approx 1.15 \mathrm{eV})$ as compared to the transfer-energy $(t \approx-0.2 \mathrm{eV})$ between adjacent molecules in the stack (see [37]). It behaves as an 1-D semiconductor along the a-axis. It is an 1-D Peierls-Hubbard system. The OA spectrum with polarization parallel to the a-axis shows a charge transfer hand $\left(\mathrm{CT}_{1}\right)$ at $\mathrm{ca} 1250 \mathrm{~nm}$, a shoulder $\left(\mathrm{CT}_{2}\right)$ at a $880 \mathrm{~nm}$, another shoulder at ca $2500 \mathrm{~nm}$ and a CTB-edge, $E_{\mathrm{g}}^{\prime}=0.95 \mathrm{eV}, 1305 \mathrm{~nm}$ ) [16,37]. Fig.8 shows that the CT'bands of small particles are shifted to higher energies as the particle size decreases [16]. TCNQ monolayers on K- or Na-glasses are self-assembled-like systems, with a CT band at ca $880 \mathrm{~nm}$ [16]. Similar results have been obtained from other anion radical salts of the type MTCNQ $(\mathrm{M}=\mathrm{Na}, \mathrm{Cu}, \mathrm{Ag}$, etc) $[16,17]$ and from some cation radical salts based on tetrathiafulvalenes [23]. Calculated OA spectra of $\mathrm{K} T^{\top} \mathrm{CNQ}$ using Hubbard-model for various values of $\mathrm{U}$, from $1.15 \mathrm{eV}$ (bulk) to $1.4 \mathrm{eV}$ (very small particles), were found in agreement with the experiments [18]. Recently,PL spectra have been observed by using a YAG laser [26].The PL spectra of KTCNQ (Fig.8) show weak bands at ca $1150 \mathrm{~nm}$. Moreover, they show upward slopes from $1250 \mathrm{~nm}$ to shorter wavelengths, perhaps, due to self-trapped excitons; they do not show particle size effects, as in the case of $\mathrm{PtCl}$ [24].
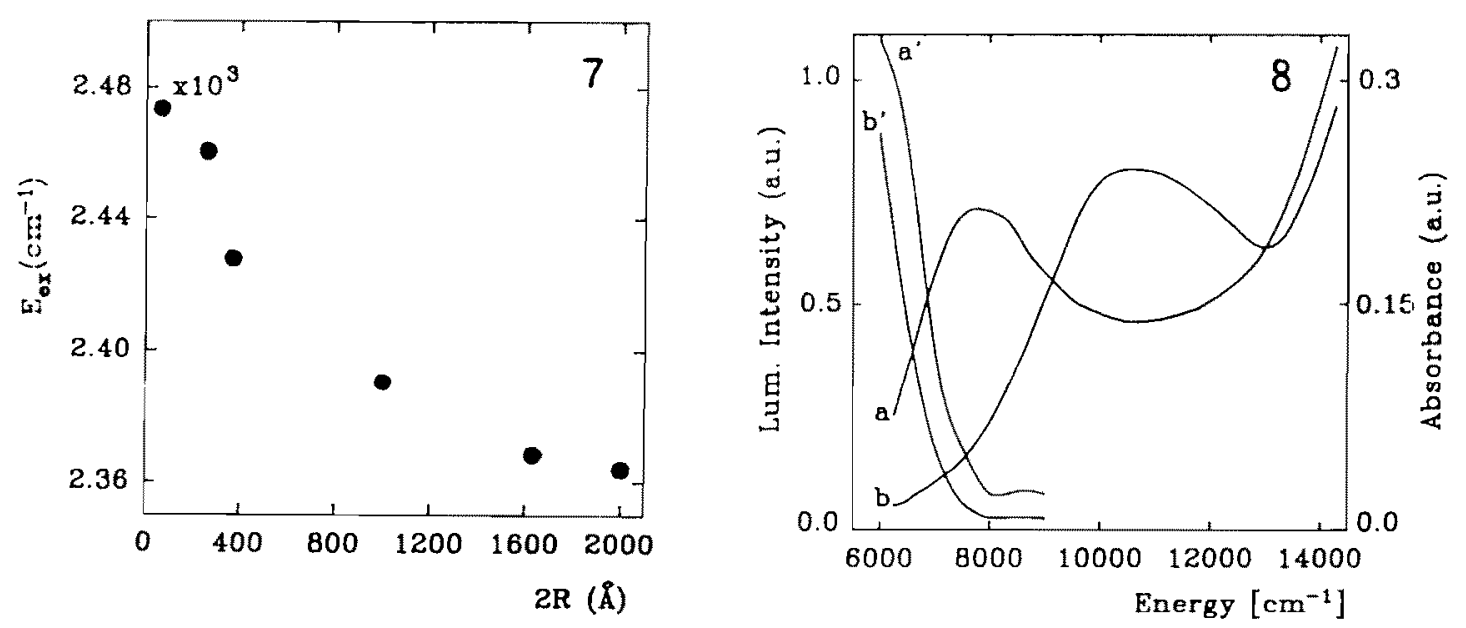

Fig.7 Particle-size dependence of the excitonic energy $\left(E_{c x}\right)$ of PtCl particles obtained from eqn.(1) and experimental data of Fig. 6 (insert).

Fig. 8. OA $(a, b)$ and PL $(c, d)$ spectra of KTCNQ particles with size ca $1000 \AA(a, c)$ and $90 \AA(b, d)[16,26]$. 


\section{Conjugated Polymers}

$\pi$-conjugated systems (e.g. polyacetylene and polydiacetylene) and $\sigma$-conjugated systems (e.g. polysilanes) are 1-D semiconductors (i.e. natural quantum wires). The linear and nonlinear optical properties of these materials are reported in a number of papers (see [36,38-47] and refs. therein). The OA spectra of polydiacetylene [38] and polysilane $[39,40]$ show sharp excitonic bands. In the case of polyacetylene, as in the case of MX complexes, a broadening mechanism amalgamates the excitonic peaks to a broad band [31]. RR and PL spectra have been observed in most cases. The RRE profiles, arising from exciton-phonon interactions, showed maxima near the excitonic bands $[38,41]$. Particle (segment) size effects in the spectra of $\pi$-conjugated polymers and polysilanes have been reported in [36,38,42] and [40], respectively. Earlier investigators interpreted the spectra of small polyenes using a modified particle in 1-D-box model [42]. The positions of the absorption peaks, which are due to excitons, are shifted to higher energies as the size of the chain decreases. The 1-D excitons have an intermediate character between Frenkel and Wannier excitons ([43] and refs therein). The Su-Schriffer-Heeger or the extended Peierls-Hubbard models were applied for calculations, concerning excitonic, and other states (see [46] and refs therein). They could be also applied for the calculations of the OA spectra of small chain polymers (oligomers) using the appropriate values of $U$ and/or other parameters $[18,46]$. For some alternative considerations see $[40,47]$.

\section{References}

1. C. Kitel "Introduction to Solid State Physics", J. Wiley and Sons, London (1976); S. Nakajima, Y. Toyazawa and R. Abe "The Physics of Elementary Excitations", Springer-Verlag, Berlin (1980); E. I. Rashba and M. D. Sturge (Eds) "Excitons", North-Holland Publ.. Co. (1982); B. E. A. Salch and M. C. Teich "Fundamental of Photonics", J. Wiley and Sons, New York (1991); M. Watanabe, T. Hayashi and R. Kato, J. Phys. Jpn. 59 (1990) 4526.

2. C.R. Berry, Phys.Rev. 161 (1967) 848.

3. G.C. Papavassiliou, J.Sol.St.Chem., 40 (1981) 330; J.Mol.Struct., 79 (1982) 395.

4. A.I. Ekimov,A.A. Onushchenko, and V.A. Tsckhomkii, Fiz.Khim. Stelka, 6 (1980) 511; A.I.Ekimov and A.A. Onushchenko, Sov., Phys.Semicond., 16 (1982) 775.

5. Al. L..Efros and A.L.E.fros, Sov. Phys. Semicond., 16 (1982) 772.

6. R. Rossetti, S. Nakahara, and I.F. Brus, J.Chem.Phys., 79 (1983) 1086, refs 3 cited therein; L. Brus, J.Chem.Phys., 79 (1983) 5566; 80 (1984) 4403; 86 (1986) 2555 also this vo.ume .

7. N. Chestnoy, T.Harris, R. Hull and L.Brus, J.Phys.Chem.,90(1986)3393; M. Grätzel, Ann.Chim. (I1al.) 77 (1987) 411; Y. Wang and N. Herron, J.Phys. Chem. , 91, 257 (1987); S.Modes and P. Lianos, Chem.Phys.Lctt. ,153 (1988) 351; A. Hässelbarth et al ibid 203 (1993) 271.

8. K.Misawa, ct al, J.Chem.Phys., 94 (1991) 4131; H.Benisty,C.M.S.-Torrés and C.Weisbusch, Phys.Rev. B44 (1991)10945; T. Sekikawa et al, Sol.St.Commun. 83 (1992) 969; M.Agata et al , ibid 76 (1990) 1(661:J.R.Kuklinski and S.Mukamel,Chem.Phys.Lett. 189 (1992) 119; Ka-Di Zhu and S.-W. Gu, Sol. State Commun. 85 (1993) 651.

9. S. Hayashi, H.Sanda, M.Agata, K. Yamamoto, Phys.Rev. B40 I (1989) 5544.

10. A.l. Ekimov, Phys.Scripta T 39 (1991) 217; M.C. Klcin F.Hach, D. Picaro and C. Flytzanis, Phys.Rev. B42 (1990) 11123; Y.Wang and N.Heron ibid. 42 (199) 7253; V.L. Colvin , A.N.Goldstein and A.P.Alivisatos, J. Am. Chem. Soc., 114 (1992) 5221;T. Rajh et al, J.Phys.Chem., 96 (1992) 4633; M. Bawendi ct al, Ann.Rev.Phys.Chem., 41 (1990) 477.

11. C.S.H. I.ee, K.Fischer, A. Vassallo, J.Hanna and I.G.Dance, Inorg.Chem. 32 (1993) 66; I. G. Dance, A. Choy and M. Scudder, J. Am. Chem. Soc. 106 (1984) 6285.

12. N. Herron, A. Suna, and Y. Wang, J.Chem.Soc. Dalton Trans. (1992) 2329; W.E. Farneth et al , Chem.Mater. 4 (1992) 916; V.I. Colvin, A.N. Goldstein, and A.P. Alivisatos, J. Am. Chem. Soc, 114 (1992) 5221; A. P. Alivisatos et al, J.Chem.Phys., 90 (1989) 3463. 
13. G.T. Einevoll, Phys.Rev. B 45 I (1992) 3410; Y. Kayanuma, Phys.Rev. B38 (1988) 9797; A. D. Andrea and R. Del Sole in "Optical Switching in Low-D Systems", Eds. H. Hang and L. Banua (NATO-ASI series B), Plenum (New York) 194 (1989) 211.

14. T.Goto, S.Saito and M.Tanaka, Sol.St.Commun. 80 (1991) 331; Z.K. Tang, Y.Nozue and T.Goto, J.Phys.Soc. Jpn., 61 (1992) 2943; M.Watanabe et al ibid 59 (1490) 4526. .

15. G.C. Papavassiliou et al, Synth. Metals, 57 (1993) 3889 and unpublished results.

16. G.C. Papavassiliou, J. Chem. Soc., Faraday Trans. II, 74, 1446 (1978); G.C. Papavassiliou and S.S. Spanou, ibid., 73 (1977) 1425.

17. E.I. Kamitsos , G.C.Papavassiliou and M.Karakassides, Mol. Cryst. Liq. Cryst., 134, (1986) 43.

18. G.C. Papavassiliou and V.M . Yartsev, Chem.Phys.Lett., 200 (1992) 209 and unpublished work.

19. G.C. Papavassiliou, J.Phys. C: Sol. State Phys., 12 (1979) L 297; G. C. Papavassiliou, T.Theophanides and R.Rapsomanikis, J. Raman Spectrosc.,8 (1979)227 ; G.C. Papavassiliou and A.D. Zdetsis, J.Chem.Soc., Faraday II 76 (1980) 104; G.C. Papavassiliou and C.S. Jacobsen, ibid. 77, (1981) 191.

20. G.C.Papavassiliou, R. Rapsomanikis, S. Mourikis, and C.S. Jacobsen, J.Chem.Soc., Faraday II, 78 (1982) 17; G.C. Papavassiliou, Chem. Scripta 17 (1981) 196.

21. G.C. Papavassiliou and D. Layek , Z. Natruforsch. 37 b (1982) 1406.

22. G. C. Papavassiliou and C.S. Jacobsen, J. Mol. Structure 115 (1984) 37.

23. G.C. Papavassiliou, H.-P.Geserich, S.Y. Yiannopoulos and J.S.Zambounis, J. Mol. Structure , 143 (1986) 215.

24. G. C. Papavassiliou, in "Mixed Valency Systems" Ed. K. Prassides, Kluwer Acad. Pub. (Netherlands) 343, (1991) 395.

25. G. C. Papavassiliou. Prog. Sol.St. Chem. 12 (1979) 195.

26. G. C. Papavassiliou et al, Mol.Cryst.I iq.Cryst.,to be published;G. C.Papavassiliou ,unpublished.

27. C. Weisbuch and B.Vinter "Quantum Semiconductor Systems",Academic Press, London (1991).

28. S.M. Weber-Milbrodt, J.T.Gammel, and A.R.Bishop,Phys.Rev. B 45 (1992) 6435;R.J. Donohoe, L.Worl, A.Arrington, A.Bulou and B.Swanson,Phys.Rev. B 45, (1992) 13185.

29. Y. Tagawa and N. Suzuki, J.Phys.Soc.Jpn., 59 (1990) 4074; K. Iwano and K. Nasu, ibid. 61 (1992) 1380; M. Suzuki and K.Nasu, Phys.Rev. , 45, (1992) 1605.

30. Y. Wada and M. Yamashita, Phys. Rev., 42 (1990) 7398; Jpn.J.Appl.Phys., 29 (1990) 2744.

31. S. Abe, J.Phys.Soc.Jpn., 58 (1989) 62; Synth.Metals, 41 (1991) 3739.

32. X. -F. He, Phys.Rev. B, 43 (1991) 2063; T.Ogawa and T.Takagahara, ibid., 44. (1991) 8138.

33. M. Tanaka, S.Kurita, Y.Okada, T.Koyima and Y. Y amata, Chem.Phys., 96 (1985) 343:

R.J.H.Clark and D.J.Michael, J.Mol.Struct., 189 (1988)i73.

34. X.Z.Huang, A. Saxena, A.R.Bishop, L.A.Worl, S.P.Love, and B.I.Swanson,Sol.St.Commun. 84 (1992) 957; M. Tanaka and S. Kurita, J.Phys.C: Sol.St. Phys.19 (1986) 3019.

35. K.Takahashi, H. Tanino and T.Yao, Jpn.J.Appl.Phys. 26 (1987) L. 97.

36. Several papers in Synth. Metals 41-43 (1991),49-51 (1992) and 54-57 (1993).

37. S.Koshihara,Y.Tokura,Y.Iwoja and T.Koda,Phys.Rev. B 44, (1991) 431; D.B.Tanner et al, ibid 16, (1977) 3283; M.Maneghetti,ibid 44 (1991) 8554 and refs.therein.

38. D. Bloor and R.R. Chance (Fds.) in "Polydiacetylencs" Martinus Nijhoff Publ., Boston; NATOASI series 102E (1985) $187,233 \mathrm{ctc}$.

39. H. Tachibana, Y. Kawabata, S.-Y.Kashihara, and Y.Takura, Sol.St. Commun. 75 (1990)5.

40. P.Tretonas, R. West, R.D. Miller, and D. Hofer, J. Pol. Sci., Pol. Lett., 21 (1983) 823; Y.

Kanemitsu, K.Suzuki, Y.Nakayoshi and Y.Masumoto, Phys.Rev. B 46 (1992) 3916.

41. I.S. Lichtmann, A. Sarhangi, and D.B. Fitchen, Chem.Scripta 17 (1981) 149.

42. H.H. Jaffe and M. Orchin in "Theory and Applications of UV Spectroscopy" J. Wiley and Sons, N.Y. (1964)

43. S. Abe, M. Schrcibcr, W.P. Su and J.Yu, Phys.Rev. B45 (1992) 9432; S.Abe, J.Yu and W.P.Su, ibid 45 (1992) 8264; K.Ishida, H.Aoki and T.Chikyu, ibid 47 (1993) 7594.

44. D.K. Campbell, Mol.Cryst. Liq. Cryst. 189 (1990) 65; D. K. Cambell, J.T.Gammel and E.Y. Loh, Jr. Phys.Rev. B 42 (1990) 475.

45. Y. Sun et al Phys.Rev. B44 (1991) 11042; Z.Y.Wong et al ibid , 45 (1992) 7850.

46. L. Yu, unpublished; W.Z. Wang et al in ref [36] herein.

47. J.Kurti and H. Kuzmany Phys.Rev. B44 (1991) 597; J. Hufrer and C.Flytazanis in "Organic Mol.Nonlinear Optics and Photonics" J.Messier et al (Eds.) Kluwer Acad. Publ. (1991) 53. 